\title{
DISPONIBILIDADE TÉRMICA PARA DIFERENTES CULTURAS AGRÍCOLAS EM REGIÃO DE CLIMA SUBTROPICAL ÚMIDO OBTIDA PELA UTILIZAÇÃO DE ÍNDICE BIOCLIMÁTICO
}

\author{
Aparecido Ribeiro de Andrade ${ }^{1}$ \\ Juliane Bereze ${ }^{2}$ \\ Rosana Martins dos Santos ${ }^{3}$ \\ João Anésio Bednarz ${ }^{4}$
}

\begin{abstract}
Resumo: Há vários sistemas de unidades bioclimáticas além dos graus-dia, embora sua utilização e limitação ainda sejam pouco conhecidas na agricultura contemporânea. Diante disso, este trabalho objetivou avaliar o desempenho do Índice Heliotérmico de Geslin (IHG) para diferentes culturas agrícolas difundidas em área de clima subtropical úmido, tendo como estudo de caso o município de Guarapuava(PR). A comparação entre o IHG ideal em cada fase produtiva e o IHG efetivamente ocorrido durante as safras de 2008 a 2013 possibilitou identificar distintos níveis de influência da disponibilidade térmica para o cultivo agrícola na região. Os dados foram cedidos pelo Instituto Agronômico do Paraná - Iapar e analisados por meio de estatística clássica, que serviu de base para a escolha do índice utilizado.
\end{abstract}

Palavras-chave: Índice heliotérmico; Produtividade agrícola; Variabilidade climática

\section{AVAILABILITY THERMAL FOR AGRICULTURAL DIFFERENT CROPS IN CLIMATE OF THE HUMID SUBTROPICAL REGION OBTAINED FROM USE OF BIOCLIMATIC INDEX}

Abstract: There are currently several bioclimatic unit systems beyond the degree-day system, although their use and limitations are still little known in contemporary agriculture. . In this context, this study evaluated the performance of the Geslin Heliothermic Index (GHI) for different crops spread in an area of humid subtropical climate, with the case study of the municipality Guarapuava (PR). The comparison between the ideal GHI for potato crops in each production phase and the actual GHI during the 2008-2013 seasons enabled to determine the influence of thermal conditions for agricultural cultivation in the region. The data were provided by the Agronomic Institute of Paraná - IAPAR and analyzed by classical statistics, which served as the basis for the choice of the index used.

Key words: Heliothermic index; Agricultural productivity; Climate variability

\section{DISPONIBILIDAD TÉRMICA PARA DIFERENTES CULTIVOS AGRÍCOLAS EN LA REGÍON DE CLIMA SUBTROPICAL HUMEDO OBTENIDO POR LA UTILIZACIÓN DEL ÍNDICE BIOCLIMÁTICO}

\footnotetext{
1 Professor do Departamento de Geografia e do Programa de Pós-Graduação (Mestrado e Doutorado) em Geografia da Unicentro. Campus Cedeteg. Guarapuava-PR. E-mail para contato: apaandrade@gmail.com

${ }^{2}$ Mestre em Geografia pelo Programa de Pós-Graduação em Geografia da Unicentro. Campus Cedeteg. Guarapuava-PR. E-mail para contato: juliane.bereze@hotmail.com

3 Acadêmica do Curso de Geografria da Unicentro. Campus Cedeteg. Guarapuava-PR. E-mail para contato: rosanynha_santos@hotmail.com

${ }^{4}$ Mestre em Geografia pela Unicentro e Doutorando em Geografia pela UEPG. E-mail para contato: joaogeo2013@gmail.com
} 
Resumen: Existen distintos sistemas de unidades bioclimáticas como los grados-día, su uso y limitación son poco conocidas en la agricultura contemporánea. Este trabajo tuvo como objetivo evaluar el desempeño del Índice Heliotérmico de Geslin (IHG) en diferentes cultivos agrícolas, distribuidos en un área subtropical húmeda, siendo objeto de estudio de caso el Municipio de Guarapuava (PR). La comparación entre el IHG ideal en cada fase productiva y el IHG efectivamente ocurrido durante las cosechas 2008 a 2013, posibilitó así identificar distintos niveles de influencia de la disponibilidad térmica para el cultivo agrícola en la región. Los datos fueron suministrados por el Instituto Agronómico de Paraná (IAPAR) y analizados por medio de estadística clásica, que sirvió de base para la elección del índice utilizado.

Palabras clave: Índice heliotérmico; Productividad agrícola; Variabilidad climática

\section{INTRODUÇÃO}

A existência da humanidade no planeta é determinada por vários fatores e as condições climáticas exercem papel fundamental dentre esses fatores. Os seres humanos possuem seu modo de vida influenciado pelas condições climáticas do local onde vivem. Por sua vez, as práticas agrícolas garantem a produção de seus alimentos, mantendo sua sobrevivência. Portanto, o cultivo agrícola é altamente dependente da variabilidade espacial e temporal dos elementos climáticos.

Santos (2000) afirma que o principal meio pelo qual a atividade humana é propícia no planeta Terra é a atmosfera, ou seja, esse é o local onde os recursos naturais são livres e atendem de maneira universal às necessidades humanas por meio da variabilidade climática, principalmente no setor agrícola.

Carvalho et al. (2011), ao avaliarem a aplicação de índices bioclimáticos para a cultura de café, concluíram que o AETR (Acúmulo de Evapotranspiração de Referência) apresentou menor variabilidade, significando ser o mais confiável. Entretanto, o Índice Heliotérmico de Geslin (IHG) apresentou uma variabilidade praticamente igual na maioria dos cultivares testados. Considerando que o IHG é bem mais simples de ser aplicado, entende-se que sua utilização deveria ser mais comum na busca da identificação de áreas mais ou menos aptas ao cultivo agrícola, pelo menos com relação à dependência da incidência radioativa.

Deffune et all., (1994) afirmam que a produção agrícola está diretamente vinculada ao processo fotossintético, variando de acordo com a quantidade de energia disponível. Nessa perspectiva, os autores utilizaram o IHG para o município de Maringá-PR, a fim de identificar a importância de aproveitamento do brilho solar pelos vegetais. 
A radiação e a insolação também influenciam significativamente no fotoperiodismo, definido como as reações das plantas diante da duração astronômica do dia. Dessa forma, o fotoperiodismo, em relação à floração das plantas, se distingue em três categorias de plantas: plantas de dias longos, plantas de dias curtos e plantas indiferentes (SCHÖFFEL, 2005).

A temperatura do solo influencia em vários processos associados ao plantio, tais como a germinação de sementes (reações bioquímicas), o crescimento do sistema radiocular (divisão de células) e a absorção de água e nutrientes (viscosidade da solução, decomposição da matéria orgânica).

A temperatura do solo é uma fração do saldo de radiação absorvida pela superfície, com isso ocorre a elevação do calor dessa superfície, ou seja, o aquecimento. Este aumento dá origem a um gradiente térmico no interior do solo, isto é, a temperatura superficial é maior do que as camadas imediatamente abaixo. Em função disto, ocorre transferência de energia da superfície para o interior do solo, que é denominada de condução térmica (PREVEDELLO, 1996).

A carência de dados meteorológicos e climáticos é um dos empecilhos para o desenvolvimento de conhecimento sobre o melhor aproveitamento da condução térmica para a produtividade agrícola. Esse impedimento é um fator importante na medida em que dificulta o planejamento do calendário agrícola.

O planejamento agrícola no município de Guarapuava é altamente vinculado as condições climáticas. No caso da cultura da batata é um dos maiores produtores do Brasil, principalmente por ter características climáticas favoráveis ao plantio dessa hortaliça do tipo tubérculo (EMBRAPA, 2002). No mesmo sentido, tanto o milho como o feijão estão entre as principais culturas agrícolas no Estado do Paraná, tanto em área cultivada, como em volume de produção e a região de Guarapuava figura entre as principais áreas produtivas. No caso do feijão, destaca-se que uma das espécies mais cultivada no Brasil é a Phaseolus vulgaris feijão comum do grupo carioca, do preto ou do especial. Nesse caso, especificamente, a região de Guarapuava é uma das mais importantes produtoras nacionais do grupo preto dessa espécie.

Guarapuava tem uma tipologia climática bem específica, pois as chuvas são constantes e as temperaturas mínimas periodicamente atingem valores abaixo de 0 , principalmente no inverno. Entretanto, essas características também são comuns nas outras estações do ano, com exceção do verão. Esse padrão dificulta a absorção radioativa do solo e consequentemente 
mantém suas temperaturas relativamente baixas. Portanto, a necessidade por mais horas de insolação e maior intensidade no brilho solar são cruciais para o desenvolvimento de cultivares agrícolas nessa região.

Segundo dados da ABBA - Associação Brasileira de Batata, na região de Guarapuava é plantado aproximadamente 4.000 ha por ano das seguintes variedades: Ágata (com aproximadamente $90 \%$ da área cultivada), Cupido, Caesar, Asterix, Vivaldi e Monalisa. A produção anual é de aproximadamente 120.000 toneladas e ocorre principalmente no período de janeiro a maio. A região conta com mais de dez lavadeiras e abastece principalmente os mercados do Paraná, São Paulo, Rio Grande do Sul, Santa Catarina, Goiás, Brasília, Minas Geras, Rio de Janeiro (ABBA, 2002).

Apesar da área de estudo (Guarapuava-PR - Figura 1) ser reconhecida como uma das maiores regiões produtoras de batata do Brasil (ABBA, 2002), praticamente não há trabalhos voltados para essa temática, portanto, fazem-se necessários estudos baseados em informações climáticas e que possam auxiliar na escolha da melhor época para plantio e colheita desse cultivar. Em relação às culturas do feijão e do milho, a literatura é mais vasta, mas praticamente inexistem trabalhos focados na influência climática sobre a produtividade desses cultivares, principalmente em regiões subtropicais úmidas do Hemisfério Sul. 


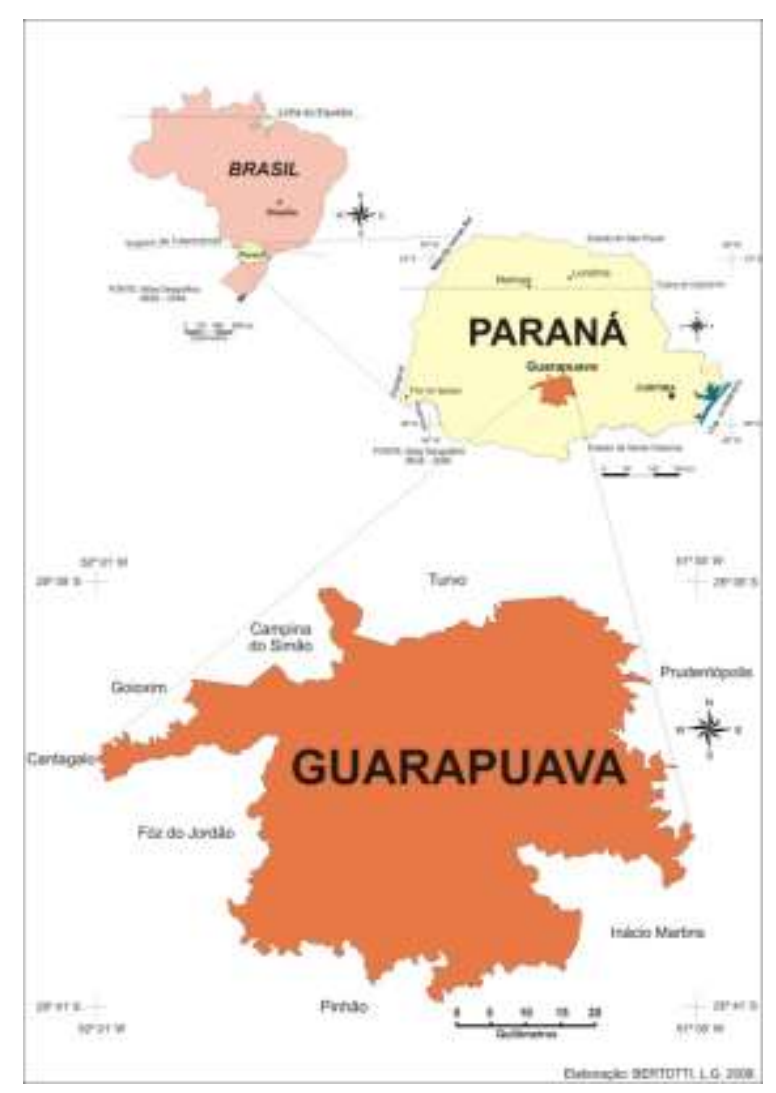

Figura 1: Localização geográfica do município de Guarapuava

\section{A cultura da batata}

Segundo Tavares (2002), a batata (Solanum tuberosum.), também conhecida como batatinha ou batata-inglesa, é nativa da América do Sul, da Cordilheira dos Andes, onde foi consumida por populações nativas em tempos que remontam a mais de 8.000 anos. No Brasil, a batata chegou junto com o plantio de outras hortaliças por volta de 1920, na região de São Paulo. A batata é considerada a principal hortaliça como preferência alimentar na mesa dos brasileiros e as principais regiões onde é cultivada são Estados do Paraná, Santa Catarina, Rio Grande do Sul, Minas Gerais e São Paulo. A área cultivada está em torno de 150 a 180.000 ha, onde se produzem anualmente 2,4 a 3,0 milhões de toneladas de batata, numa produtividade média de $20,5 \mathrm{t} / \mathrm{ha}$.

A cultura desenvolve-se em altitudes de até $4.300 \mathrm{~m}$, necessita de um período de 90 a 140 dias para completar seu ciclo e o conhecimento do cultivar e seu ciclo fenológico são de suma importância para alcançar o máximo potencial produtivo. 
A batata pode ser plantada o ano todo, a temperatura exigida à noite é de 10 a $16^{\circ} \mathrm{C}$ e durante o dia é de 20 a $25^{\circ} \mathrm{C}$. Temperaturas noturnas superiores a $20^{\circ} \mathrm{C}$ reduzem a tuberização, pois a respiração aumenta e o crescimento dos tubérculos é retardado. A planta exige diferença entre as temperaturas diurnas e noturnas em torno de $10^{\circ} \mathrm{C}(\mathrm{SEAB}, 2012)$.

A produção de batatas na região de Guarapuava (PR) foi introduzida por imigrantes japoneses na década de 1960, juntamente com a Cooperativa Agrícola de Cotia. A região é bastante propícia à produção de batatas devido ao clima ameno e solos férteis. A produção de batatas na região abrange os seguintes municípios: Guarapuava, Pinhão, Candói, Reserva do Iguaçu, Goioxim, Cantagalo, Turvo, Prudentópolis e Santa Maria do Oeste.

O plantio da batata ocorre em época distinta na região de Gurapuava. O mais comum é o denominado "Plantio das águas" que ocorre de setembro a novembro/dezembro, em localidades altas e sua área de plantio é maior, chegando a 55\% do total. Outra época bastante comum é a de "Plantio da seca", compreendendo o intervalo entre fevereiro a abril, em localidades altas e médias e sua parcela de contribuição na produção total chega a 32\%. Existe também o "Plantio de inverno", período de maio a julho e se restringe à área de baixa altitude, com uma parcela de $13 \%$ no total da produção de batata na região de Guarapuava.

Segundo dados obtidos empiricamente junto à Secretaria Municipal de Agricultura de Guarapuava, a espécie produzida na região é a "Ágata”, cujas principais características são maturação precoce com bom desenvolvimewnto das hastes finais espalhadas e folhas grandes de cor verde claro. Seus folículos são grandes e sua inflorescência é pequena com flores brancas. O tubérculo proveniente é grande, com aspecto oval-alongado e polpa amarela-clara com baixo teor de massa matéria seca (TAVARES, 2002).

Na Tabela 1 é apresentado o calendário agrícola para o plantio e produção da batata na região de Guarapuava, separados por estádios produtivos.

O Estádio I, do plantio até a emergência das hastes, com duração de uma a duas semanas, chega até a terceira semana. No Estádio II, compreende da emergência ao início da tuberização, se inicia na quarta ou quinta semana após o plantio, com a adubação de cobertura, seguida da amontoa. Nesse estádio aumenta a exigência de água. No Estádio III ocorre o início da tuberização ( $6^{\mathrm{a}}$ semana) e vai até a planta atingir o máximo desenvolvimento vegetativo ( $8^{\mathrm{a}}$ a $10^{\mathrm{a}}$ semana após o plantio). Nesse estádio, a planta atinge a máxima absorção de nutrientes, máxima exigência de água, podendo ocorrer ou não o florescimento. O desenvolvimento é acelerado na parte aérea e ocorre o acúmulo de 
fotoassimilados nos tubérculos. Por fim, no Estádio IV, que compreende do pico da vegetação $\left(10^{\mathrm{a}}\right.$ semana) até a senescência da planta, ocorre grande incremento de peso dos tubérculos. $\mathrm{O}$ amarelecimento se inicia na $12^{\mathrm{a}}$ ou $14^{\mathrm{a}}$ semana após o plantio. O término do processo produtivo ocorre quando a planta seca e os tubérculos ficam maduros $\left(14^{\mathrm{a}}\right.$ a $16^{\mathrm{a}}$ semanas)

Tabela 1:Esquema do ciclo fenológico da cultura da batata (setembro a dezembro)

\begin{tabular}{|c|c|c|c|c|c|c|c|c|c|c|c|c|c|c|c|c|}
\hline Estádios & $1^{\mathrm{a}}$ & $2^{\mathrm{a}}$ & $3^{\mathrm{a}}$ & $4^{\mathrm{a}}$ & $5^{\mathrm{a}}$ & $6^{\mathrm{a}}$ & $7^{\mathrm{a}}$ & $8^{a}$ & $9^{\mathrm{a}}$ & $10^{\mathrm{a}}$ & $11^{\mathrm{a}}$ & $12^{\mathrm{a}}$ & $13^{\mathrm{a}}$ & $14^{\mathrm{a}}$ & $15^{\mathrm{a}}$ & $16^{\mathrm{a}}$ \\
\hline Estádio I & $\mathrm{X}$ & $\mathrm{X}$ & $\mathrm{X}$ & & & & & & & & & & & & & \\
\hline Estádio II & & & $X$ & $X$ & $X$ & & & & & & & & & & & \\
\hline Estádio III & & & & & & $\mathrm{X}$ & $X$ & $X$ & $X$ & $\mathrm{X}$ & & & & & & \\
\hline Estádio IV & & & & & & & & & & $X$ & $X$ & $\mathrm{X}$ & $X$ & $X$ & $X$ & $\mathrm{X}$ \\
\hline
\end{tabular}

Fonte: (ABBA, 2002) e (TAVARES, 2002). Organizado e adaptado por BEREZE, (2014).

\section{A cultura do milho}

O milho é uma das principais culturas agrícolas no Estado do Paraná, tanto em área cultivada, como em volume de produção; é um cereal de ampla utilidade mundial. Sua utilização é tanto para o consumo humano, como animal, além de ser amplamente aproveitado em algumas atividades industriais.

O milho é cultivado em aproximadamente 1,5 milhões/hectare no Paraná (PR), com rendimento médio de aproximadamente 5 toneladas/hectare. Na região Centro-Sul do Paraná, têm-se obtido altos rendimentos, relacionados entre outros fatores à sua maior aptidão climática (FONTANA e BAYER, 2008).

Fontana e Bauer (2008) ainda afirmam que em relação ao manejo do solo, a região Centro-Sul do Paraná está em estágio avançado de adoção de sistemas conservacionistas, evidenciado pela grande expressão do sistema plantio direto. A cultura do milho, segundo esses autores, pode ser dividida em oito estádios de desenvolvimento, a saber:

Estádio I: emergência (até 01 semana, $\left.10^{\circ} \mathrm{C}\right)$; Estádio II: uma folha desenvolvida (01 a 02 semanas, $21^{\circ} \mathrm{C}$ ); Estádio III: três folhas desenvolvidas (02 a 04 semanas, $21^{\circ} \mathrm{C}$ ); Estádio IV: sete folhas desenvolvidas $\left(04\right.$ a 06 semanas, $\left.21^{\circ} \mathrm{C}\right)$; Estádio V: rápido crescimento (06 a 08 semanas, $21^{\circ} \mathrm{C}$ ); Estádio VI: pendoamento (08 a 09 semanas, $\left.21^{\circ} \mathrm{C}\right)$; 
Estádio VII: florescimento e polinização (09 a 10 semanas, $\left.21^{\circ} \mathrm{C}\right)$; Estádio VIII: maturização fisiológica (10 a 17 semanas, $\left.25^{\circ} \mathrm{C}\right)$ (Tabela $2 \mathrm{a}$ e $\left.2 \mathrm{~b}\right)$.

Tabela 2a: Estádios de desenvolvimento fenológico da cultura do milho (setembro a dezembro)

\begin{tabular}{|c|c|c|c|c|c|c|c|c|c|}
\hline Estádios & $1^{\mathrm{a}}$ & $2^{a}$ & $3^{a}$ & $4^{\mathrm{a}}$ & $5^{a}$ & $6^{\mathrm{a}}$ & $7^{\mathrm{a}}$ & $8^{a}$ & $9^{\mathrm{a}}$ \\
\hline Estádio I & $\mathrm{X}$ & & & & & & & & \\
\hline Estádio II & $X$ & $\mathrm{X}$ & & & & & & & \\
\hline Estádio III & & $\mathrm{X}$ & $\mathrm{X}$ & $\mathrm{X}$ & & & & & \\
\hline Estádio IV & & & & $X$ & $X$ & $\mathrm{X}$ & & & \\
\hline Estádio V & & & & & & $\mathrm{X}$ & $\mathrm{X}$ & $\mathrm{X}$ & \\
\hline Estádio VI & & & & & & & & $X$ & $X$ \\
\hline Estádio VII & & & & & & & & & $\mathrm{X}$ \\
\hline Estádio VIII & & & & & & & & & \\
\hline
\end{tabular}

Tabela 2b: Continuação da Tabela 2a

\begin{tabular}{lllllllll} 
Semanas & $10^{\mathrm{a}}$ & $11^{\mathrm{a}}$ & $12^{\mathrm{a}}$ & $13^{\mathrm{a}}$ & $14^{\mathrm{a}}$ & $15^{\mathrm{a}}$ & $16^{\mathrm{a}}$ & $17^{\mathrm{a}}$ \\
\hline Estádio VII & $\mathrm{X}$ & & & & & & & \\
Estádio VIII & $\mathrm{X}$ & $\mathrm{X}$ & $\mathrm{X}$ & $\mathrm{X}$ & $\mathrm{X}$ & $\mathrm{X}$ & $\mathrm{X}$ & $\mathrm{X}$ \\
\hline
\end{tabular}

Fonte: Embrapa (2005), organizado por SANTOS, Rosana M. (2014)

\section{A cultura do feijão}

O feijão é cultivado por pequenos e grandes produtores, em diversificados sistemas de produção e em todas as regiões brasileiras. O feijoeiro comum reveste-se de grande importância econômica e social.

Embora esse alimento seja conhecido pelo nome comum de feijão, nem todas as plantas são da mesma espécie. Entre a família das leguminosas, as principais espécies de feijão cultivadas no Brasil são Phaseolus vulgaris - feijão comum do grupo carioca, do preto ou do especial; Vigna unguiculata - também conhecido como feijão-caupi, vigna, feijão-dacolônia, feijão-da-estrada ou feijão-de-corda; e o Cajanus cajan - feijão-guandu, andu ou ervilha-de-pombo (EMBRAPA, 2012). 
Segundo MAPA (2012) dependendo do cultivar e da temperatura ambiente, esse cultivar pode apresentar ciclos variando de 65 a 100 dias, tornando-o uma cultura apropriada para compor, desde sistemas agrícolas intensivos irrigados, altamente tecnificados, até aqueles com baixo uso tecnológico, principalmente de subsistência. O feijão preto, espécie mais produzida na área de estudo, é mais popular no Rio Grande do Sul, Santa Catarina, sul e leste do Paraná, Rio de Janeiro, sudeste de Minas Gerais e sul do Espírito Santo.

A safra desse grão é divida em três etapas: a primeira, conhecida como safra das águas é assim denominada porque o plantio e a colheita são beneficiados pelo alto índice de chuvas. O plantio dessa safra no centro-sul do Paraná vai de agosto a dezembro; A safra é feita no período com menor índice de chuva (março a junho), por isso é denominada de safra da seca. O plantio ocorre de dezembro a março. Já a terceira (safra irrigada) tem o período de abril a junho. O feijão pode ser colhido, em média, 90 dias após ser plantado (MAPA, 2012)

A temperatura e as chuvas são os elementos climáticos que mais influenciam na produção do feijão. As altas temperaturas prejudicam o florescimento e a frutificação do feijoeiro, enquanto as baixas podem provocar a perda das flores. Alta temperatura acompanhada de baixa umidade relativa do ar e ventos fortes têm maior influência na retenção de vagens.

MAPA (2012) afirma também que o feijoeiro é uma planta com raiz delicada, com sua maior parte concentrada na camada de até $20 \mathrm{~cm}$ de profundidade do solo, por isso, deve-se ter um cuidado especial na escolha da área. Solos pesados, compactados, sujeitos a formar crosta na superfície ou ao encharcamento, não são adequados para a cultura.

O cultivar considerado no presente estudo é o do feijão preto BRS Campeiro - tem ciclo semiprecoce (75 a 90 dias) com alto potencial produtivo $(4.230 \mathrm{~kg} / \mathrm{ha})$, excelente qualidade culinária e porte ereto - o que facilita a colheita mecânica. Essa espécie é indicada para o cultivo nos Estados de São Paulo, Santa Catarina, Paraná, Rio Grande do Sul, Sergipe, Pernambuco, Mato Grosso, Mato Grosso do Sul e Rondônia, apresentando cinco estádios de desenvolvimento (EMBRAPA, 2012).

Estádio I: germinação - processo em que a semente começa a formar um broto ou mudas (01 semana, $\left.10^{\circ} \mathrm{C}\right)$; Estádio II: crescimento - a fase de crescimento é de aproximadamente cinco semanas, dependendo da quantidade de luz solar (02 a 05 semanas, $\left.18^{\circ} \mathrm{C}\right)$; Estádio III: reprodução - os ovários das flores começam a crescer em vagens (06 a 08 semanas, $\left.20^{\circ} \mathrm{C}\right)$; 
Estádio IV: feijão verde imaturo (09 a 11 semanas, $22^{\circ} \mathrm{C}$ ); Estádio V: estourando vagens e feijão novo - amadurecimento e colheita (12 semanas, $24^{\circ} \mathrm{C}$ ), conforme descrito na Tabela 3.

Tabela 3: Estádios de desenvolvimento da cultura do feijão (Plantio das águas)

\begin{tabular}{|c|c|c|c|c|c|c|c|c|c|c|c|c|}
\hline Semanas & $1^{a}$ & $2^{a}$ & $3^{\mathrm{a}}$ & $4^{a}$ & $5^{a}$ & $6^{a}$ & $7^{a}$ & $8^{\mathrm{a}}$ & $9^{a}$ & $10^{\mathrm{a}}$ & $11^{\mathrm{a}}$ & $12^{\mathrm{a}}$ \\
\hline Estádio I & $\mathrm{X}$ & & & & & & & & & & & \\
\hline Estádio II & & $\mathrm{X}$ & $\mathrm{X}$ & $X$ & $X$ & & & & & & & \\
\hline Estádio III & & & & & & $\mathrm{X}$ & $\mathrm{X}$ & $\mathrm{X}$ & & & & \\
\hline Estádio IV & & & & & & & & & $\mathrm{X}$ & $\mathrm{X}$ & $\mathrm{X}$ & \\
\hline Estádio V & & & & & & & & & & & & $X$ \\
\hline
\end{tabular}

Fonte: Embrapa (2005), organizado por SANTOS (2014).

\section{Procedimentos metodológicos da pesquisa}

O município de Guarapuava é desprovido de informações embasadas em índices bioclimáticos. Entretanto, essas informações são extremamente importantes, pois definem as necessidades bioclimáticas (temperatura e fotoperíodo) das espécies cultivadas.

Como as condições do tempo não podem ser totalmente previstas, a agricultura é uma atividade de risco em virtude de secas prolongadas, veranicos (períodos secos dentro de uma estação chuvosa) e chuvas excessivas.

Geslin (1944) elaborou uma metodologia de avaliação considerando a disponibilidade de energia para alguns cereais de estação fria. Utilizando a cultura de trigo, na França, esse autor estabeleceu uma metodologia de caracterização bioclimática (exigência térmica e de fotoperíodo) com base em um índice heliotérmico, posterior denominado de Índice Heliotérmico de Geslin - IHG, em sua homenagem.

O IHG pode ser usado para melhorar a produtividade agrícola e basicamente se ampara no cálculo do somatório do produto da temperatura média do ar e do fotoperíodo em um determinado intervalo, normalmente associado ao período produtivo de um cultivar qualquer.

Esse índice é bastante utilizado em culturas anuais e alguns autores (CUNHA et al., 1997 e 1999, SENTELHAS, 1998) já desenvolveram trabalhos utilizando-o para caracterização bioclimática de culturas de centeio e girassol, por exemplo. 
Nesse trabalho utilizou-se o IHG (GESLIN, 1944) como padrão de avaliação para a necessidade bioclimática da batata, do feijão e do milho. Tal escolha ocorreu em virtude de que este índice foi desenvolvido para cereais de clima frio (trigo), com necessidades de temperatura e horas de insolação muito parecidas com essas culturas.

O IHG é calculado pelo somatório do produto da temperatura média do ar e do fotoperíodo em um determinado período. Esse índice é bastante utilizado em culturas anuais.

Para a realização do presente estudo foram obtidos dados de temperatura e de insolação dos anos de 2008 a 2013, fornecidos pelo Instituto Agronômico do Paraná - IAPAR.

Para analise dos dados utilizaram-se de recursos de planilha eletrônica, através do Microsoft Windows Excel, versão 2007. O IHG foi calculado segundo a fórmula proposta por Geslin (1944):

\section{IHG $=(1 / 100) \times \sum(\operatorname{Tmed} \times \mathbf{n})$}

Em que: Tmed é a temperatura média $\left({ }^{\circ} \mathrm{C}\right)$ e $\mathbf{n}$ é o fotoperíodo médio (horas) do período considerado.

Os dados foram tabulados em planilha eletrônica como o exemplo da Tabela 4. Percebe-se que no período de $1^{\circ}$ a 14 de setembro de 2008, o IHG obtido para a região de Guarapuava é de 20.6.

Tomando como exemplo a cultura da batata, em seus diversos estádios produtivos, foi realizada uma adaptação da metodologia proposta por ABBA (2002) e Embrapa (2005). Essa adaptação definiu que as temperaturas ideais para o melhor desenvolvimento do cultivar se dá da seguinte forma: Estádio $\mathrm{I}=10^{\circ} \mathrm{C}$; Estádio $\mathrm{II}=16^{\circ} \mathrm{C}$; Estádio $\mathrm{III}=19^{\circ} \mathrm{C}$; Estádio $\mathrm{IV}=$ $23^{\circ} \mathrm{C}$.

Contudo, ao se considerar a temperatura ideal (T.ideal) para a cultura da batata, o IHG deveria ser 10.1. Isso significa que as condições bioclimáticas para essa cultura estiveram bem acima do necessário.

Logo, IHG Real $=(1 / 100) \times \sum($ Tmed $\times$ n $)$, em que IHG Real $=0,1 \times 2060,5=20,6 . \mathrm{Da}$ mesma forma, IHG Ideal $=(1 / 100) \times \sum($ Tmed x n $)$, em que IHG Ideal $=0,1 \times 1010=10,1$

Depois dessa tabulação, os dados foram agrupados em uma única tabela, o que possibilitou mensurar o IHG do município de Guarapuava para todo o período fenológico das culturas pesquisadas e o IHG Ideal para que a máxima produtividade fosse atingida, considerando a disponibilidade de energia radiante.

Tabela 4: Exemplificação da tabulação de dados para obtenção do IHG 


\begin{tabular}{lcccrc}
\hline 2008 & $\begin{array}{c}\text { Insolação } \\
(\mathbf{n})\end{array}$ & $\begin{array}{c}\text { T.med } \\
\left({ }^{\circ} \mathbf{C}\right)\end{array}$ & $\begin{array}{c}\text { T. ideal } \\
\left({ }^{\circ} \mathbf{C}\right)\end{array}$ & T.med*n & n*T.ideal \\
\hline $01 /$ set & 9.5 & 19.0 & 10 & 180.5 & 95 \\
$02 /$ set & 9.8 & 19.5 & 10 & 191.1 & 98 \\
$03 /$ set & 9.2 & 21.7 & 10 & 199.6 & 92 \\
$04 /$ set & 6.3 & 21.6 & 10 & 136.1 & 63 \\
$05 /$ set & 8.9 & 21.3 & 10 & 189.6 & 89 \\
$06 /$ set & 1.6 & 20.9 & 10 & 33.4 & 16 \\
$07 /$ set & 9.6 & 20.1 & 10 & 192.9 & 96 \\
$08 /$ set & 9.5 & 18.5 & 10 & 175.7 & 95 \\
$09 /$ set & 7.7 & 20.6 & 10 & 158.6 & 77 \\
10/set & 9.6 & 20.5 & 10 & 196.8 & 96 \\
11/set & 6.7 & 20.8 & 10 & 139.3 & 67 \\
12/set & 0.0 & 21.3 & 10 & 0 & 0 \\
13/set & 3.4 & 21.7 & 10 & 73.7 & 34 \\
14/set & 9.2 & 21.0 & 10 & 193.2 & 92 \\
\hline
\end{tabular}

Dados cedidos pelo Iapar (2014) e organizados por BEREZE (2014).

Após a tabulação e cálculo dos dados de temperatura média do ar e horas de insolação para os períodos das safras de 2008 a 2013, obtiveram-se os resultados constantes nas Tabelas 5, 6 e 7, em que foi possível identificar os IHGs Ideais para cada estádio das culturas selecionadas. Da mesma forma, também se identificou o IHG efetivamente ocorrido para o município de Guarapuava no mesmo período.

Os resultados constantes nas respectivas tabelas são representados pela cor vermelha $(+)$ e azul (-) para se estabelecer se o índice foi acima (+) ou abaixo (-) do esperado para o referido cultivar. Dessa maneira, nos estádios e anos em que o índice foi acima do ideal, considerou-se como positivo, e naqueles em que o IHG foi abaixo do ideal considerou-se negativo.

\section{Resultados e discussões}

Os resultados da Tabela 5 indicam que os anos de 2009 e 2011 são os únicos que apresentaram um IHG favorável em todos os estágios fenológicos da cultura da batata. Os demais apresentaram oscilação frequente. O ano de 2008 foi o que apresentou IHG menos favorável, com o terceiro e quarto estágio pouco propícios para o desenvolvimento da hortaliça desde o início da tuberização até seu amadurecimento. 
Tabela 5: IHG Ideal e IHG Real para a batata Ágata nas safras de 2008 a 2013, por estádios fenológicos.

\begin{tabular}{|c|c|c|c|c|c|c|}
\hline & \multicolumn{2}{|c|}{2008} & \multicolumn{2}{|c|}{2009} & \multicolumn{2}{|c|}{2010} \\
\hline & IHG Real & IGH Ideal & IHG Real & IGH Ideal & IHG Real & IGH Ideal \\
\hline Est. I & & 10.1 & & 4.7 & & 10.6 \\
\hline Est. II & & 22.8 & & 16.3 & & 14.5 \\
\hline Est. III & & 32.6 & & 43.8 & & 52.6 \\
\hline \multirow[t]{3}{*}{ Est. IV } & & 82.2 & & 50.2 & & 44.5 \\
\hline & \multicolumn{2}{|c|}{2011} & \multicolumn{2}{|c|}{2012} & \multicolumn{2}{|c|}{2013} \\
\hline & IHG Real & IHG Ideal & IHG Real & IGH Ideal & IHG Real & IGH ideal \\
\hline Est. I & & 10.2 & & 11.4 & & 10.8 \\
\hline Est. II & & 26.5 & & 22.3 & & 15.6 \\
\hline Est. III & & 48.6 & & 37.9 & & 45.1 \\
\hline Est. IV & & 70.2 & & 55.4 & & 53.3 \\
\hline
\end{tabular}

Elaborado por BEREZE, 2014

A Tabela 6 demonstra os resultados para o IHG do milho, na qual é possível observar que durante o período de 2008 a 2013, a evolução do índice não acontece da mesma forma em todos os períodos.

Nos anos de 2009, 2010, 2011 e 2012, o IHG de Guarapuava se manteve superior ao IHG Ideal para a cultura do milho em todos os estádios, enquanto no ano de 2013 apresenta apenas o terceiro estádio com índice abaixo do ideal.

Tabela 6: Índice Heliotérmico de Geslin Ideal e obtido para a cultura do milho em Guarapuava - 2008 a 2013.

\begin{tabular}{lcccccc}
\hline & \multicolumn{2}{c}{2008} & \multicolumn{2}{c}{2009} & \multicolumn{2}{c}{2010} \\
\hline & IHG Real & IGH Ideal & IHG Real & IGH Ideal & IHG Real & IGH Ideal \\
Est. I & 9,4 & 5,4 & 7,0 & 2,7 & 12,4 & 4,9 \\
Est. II & $\mathbf{8 , 2}$ & 9,6 & 4,5 & 4,1 & 13,4 & 11,9
\end{tabular}




\begin{tabular}{|c|c|c|c|c|c|c|}
\hline Est. III & 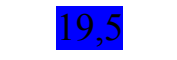 & 23,6 & 15,8 & 14,5 & 16,7 & 14,8 \\
\hline Est. IV & & 16,0 & & 14,4 & & 16,1 \\
\hline Est. V & & 13,7 & & 16,0 & & 18,6 \\
\hline Est. VI & & 5,2 & & 15,7 & & 14,7 \\
\hline Est. VII & & 7,2 & & 9,1 & & 12,7 \\
\hline \multirow[t]{3}{*}{ Est. VIII } & & 105,1 & 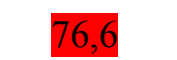 & 69,2 & & 71,3 \\
\hline & \multicolumn{2}{|c|}{2011} & \multicolumn{2}{|c|}{2012} & \multicolumn{2}{|c|}{2013} \\
\hline & IHG Real & IHG Ideal & IHG Real & IGH Ideal & IHG Real & IGH ideal \\
\hline Est. I & & 4,9 & & 6,4 & & 3,7 \\
\hline Est. II & 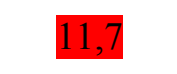 & 11,0 & 13 & 10,4 & & 14,6 \\
\hline Est. III & & 21,6 & & 22,6 & & 13,7 \\
\hline Est. IV & & 20,2 & & 15,8 & & 19,0 \\
\hline Est. V & & 21,7 & 21 & 17,9 & & 15,9 \\
\hline Est. VI & 12 , & 11,9 & & 6,9 & & 11,8 \\
\hline Est. VII & & 12,8 & & 7,7 & & 9,5 \\
\hline Est. VIII & 94 & 89,7 & 88,9 & 80,9 & & 86,7 \\
\hline
\end{tabular}

Elaborado por SANTOS, R.M. (2014)

Já no ano de 2008, o padrão é um pouco diferente e o índice fica abaixo do ideal do segundo ao quinto e no oitavo estádios. Entretanto, no primeiro, sexto e sétimo estádios, o IHG também ficou acima do ideal.

A produtividade média de milho, para os anos de 2008 e 2013, foi a menor e a maior, respectivamente, dentro do período de estudo (SEAB, 2013). Essa constatação indica que o IHG baixo, o que ocorreu em 2008, está associado à baixa produtividade do milho.

Os dados referentes ao cultivar feijão, no município de Guarapuava, foram dispostos da mesma forma, o que possibilitou analisar que o IHG do município encontra-se acima do esperado em todos os estádios para os seis anos analisados (Tabela 7).

Tabela 7: Índice Heliotérmico de Geslin Ideal e obtido para a cultura do feijão em Guarapuava - 2008 a 2013. 


\begin{tabular}{|c|c|c|c|c|c|c|}
\hline & \multicolumn{2}{|c|}{2008} & \multicolumn{2}{|c|}{2009} & \multicolumn{2}{|c|}{2010} \\
\hline & IHG Real & IGH Ideal & IHG Real & IGH Ideal & IHG Real & IGH Ideal \\
\hline Est. I & & 13,4 & & 8,7 & 16,8 & 12,4 \\
\hline Est. II & & 33,3 & & 20,6 & 101,0 & 30,8 \\
\hline Est. III & & 18,4 & & 22,1 & & 17,4 \\
\hline Est. IV & & 17,6 & & 27,0 & & 31,4 \\
\hline \multirow[t]{3}{*}{ Est. V } & & 13,0 & & 23,2 & & 27,5 \\
\hline & \multicolumn{2}{|c|}{2011} & \multicolumn{2}{|c|}{2012} & \multicolumn{2}{|c|}{2013} \\
\hline & IHG Real & IHG Ideal & IHG Real & IGH Ideal & IHG Real & IGH Ideal \\
\hline Est. I & & 11,0 & & 16,9 & & 8,6 \\
\hline Est. II & & 43,4 & & 41,0 & & 32,5 \\
\hline Est. III & & 19,4 & & 23,8 & & 22,0 \\
\hline Est. IV & 76,6 & 31,1 & 87 & 22,7 & & 27,9 \\
\hline Est. V & 72 & 24,5 & & 14,3 & & 20,4 \\
\hline
\end{tabular}

Elaborado por BEDNARZ, J. A. (2014)

Nota-se que o IHG foi acima do elevado para todo o período analisado, demonstrando excedente de potencial calorífico para todas as safras de feijão. A produtividade média do feijão nesse período foi crescente (SEAB, 2013), ou seja, de 2007 a 2013 a produtividade se manteve estável com ligeira tendência de aumento, tanto que em 2007 foi de 1.400 t/ha, enquanto em 2013 foi de 1.500 t/ha. Dessa maneira, percebe-se que o excedente calorífico constatado foi benéfico ao cultivar.

\section{Considerações Finais}

As análises efetuadas nesse trabalho estabelecem uma média de IGH ideal para a cultura da batata no município de Guarapuava-PR da seguinte forma: Estádio I = 9.63; Estádio II = 19.66; Estádio III = 43.43; e Estádio IV = 59.28. O conhecimento desse índice pode colaborar para se estabelecer um calendário agrícola local de plantio da batata, possibilitando possível aumento da sua produtividade e melhor adaptação da cultura ao clima local e regional, sem a 
necessidade de técnicas para aquecimento/resfriamento artificiais, diminuindo do custo de produção.

Observa-se também que o IHG manteve-se elevado no Estádio I em todos os anos analisados. Como esse estádio é o mais curto, com duração de uma a duas semanas, esse resultado não influencia de forma tão significativa na produtividade. Já nos anos de 2009 e 2011, o IHG foi maior do que o necessário em todas as fases fenológicas do plantio até a colheita, favorecendo o desenvolvimento da batata. Esse fato foi comprovado, pois a produtividade de batata para Guarapuava, em 2009 e 2011 , foi de $24.637 \mathrm{~kg} / \mathrm{ha}$ e 34.678 $\mathrm{kg} / \mathrm{ha}$, respectivamente.

Com relação às culturas de milho e feijão, foi possível concluir que o IHG se mostrou inferior ao índice ideal para a região de Guarapuava somente no ano de 2008, em que a produtividade foi a menor do período. Isso demonstra que a região é propícia à produção de milho, pois quanto maior a disponibilidade calórica, melhor a produtividade desse cultivar.

Para a cultura do feijão das águas, os resultados evidenciaram que todos os estádios da cultura obtiveram valores superiores ao necessário para o bom desenvolvimento fenológico da planta. Fato favorável também e, inclusive, com maior disponibilidade de energia que a cultura do milho.

Fazendo uma comparação das culturas, pode-se concluir que a cultura melhor adaptada, baseada no IHG de Guarapuava, é a do feijão, em virtude de apresentar índices superiores em todos os estádios analisados, o que é benéfico.

Por fim, sugere-se que essa relação seja mais bem estudada para novas épocas de plantio das culturas analisadas, tentando encontrar uma relação mais significativa com dados mais amplos, tanto de produtividade, quanto de disponibilidade calorífica, o que não foi possível nesse trabalho. Apesar de o IHG ter demonstrado boas condições caloríficas para o plantio desses cultivares, a produtividade pode ser melhorada, caso os períodos mais favoráveis sejam identificados e o IHG pode ajudar nesse processo.

\section{Agradecimentos}

Agradecemos aos professores Jackson Kawakami e Sidnei Osmar Jadoski, docentes do Departamento e do Programa de Pós-Graduação em Agronomia da Unicentro, pelas 
informações e sugestões de material bibliográfico sobre a fenologia dos cultivares selecionados para o presente estudo.

\section{Referências bibliográficas}

ABBA - Associação Brasileira da Batata. Produção de Batata - Região de Guarapuava. 2002. Disponível em <http://www.abbabatatabrasileira.com.br/revista14 008.htm > acesso em 10 maio 2014.

BOHL, W. H. and JOHNSON, S. B. (eds.) Commercial Potato Production in North America, P. 67-72. The Potato Association of America Handbook, Supplement. Vol. 57 of USDA Handbook 267. Orono, ME: The Potato Association of America. 2010.

CARVALHO, Hudson de P.; MELO Benjamim; RABELO, Paulo G.; SILVA, Claudio R.; CAMARGO, Reginaldo. Índices bioclimáticos para a cultura de café. Revista Brasileira de Eng. Agrícola Ambiental, v.15, n.6, p.601-606, 2011.

CUNHA, R. G. da; SCHEEREN, P. L.; RODRIGUES, O.; DEL DUCA, L. J. A.; FIORINI, C. M.; SILVA, C.F.L. Bioclimatologia de trigos sul-brasileiros. Revista Brasileira de Agrometeorologia, Santa Maria, 5:195-198, 1997

CUNHA, R. G. da e SILVA, M. S.; ÁRIAS, G.; DAlMAGO, G. A. Caracterização bioclimática de cevadas brasileiras. Revista Brasileira de Agrometeorologia, Santa Maria, 7:201-206, 1999.

DEFFUNE, G; PAULINO, E. V. S; BULLA. C. Determinação do Índice Heliotérmico de Geslin para Maringá - PR, 1990 e 1991. Boletim de Geografia. Maringá: EDUEM, v. 12, n. 1, 1994.

EMBRAPA. Árvore do Conhecimento da Batata: Temperatura. 2002. Disponível em http://www.agencia.cnptia.embrapa.br/gestor/batata/arvore/CONT000gnc4knh202wx5ok0eda cxl5y26tik.html acesso em 12 maio 2014.

EMBRAPA. Sistemas de Produção. ISSN 1807-1805. Versão Eletrônica - Dez./2005. Disponível em http://sistemasdeproducao.cnptia.embrapa.br/FontesHTML/Feijao/ultivodoFeijaoComumRO/ clima.htm. Acessado em 29 abr 2014

EMBRAPA. Desenvolvimento econômico, social e ambiental da agricultura familiar pelo conhecimento agroecológico - Feijão: Cultivo do Feijoeiro Comum. 2012. Disponível em http://sistemasdeproducao.cnptia.embrapa.br/FontesHTML/Feijao/CultivodoFeijoeiro/index.h $\underline{\text { tm. }}$. Acessado em 20 de fevereiro de 2014.

FONTANA, S.W.V; BAYER, C. Adubação nitrogenada para auto rendimento do milho em plantio direto na região centro sul do Paraná. Fundação Agrária de Pesquisa Agropecuária, 2008. 32p.

GESLIN, H. Étude des lois de croissance d'une plante en fonction des facteurs du climat (température et radiation solaire) contribution a I'étude du climat du blé. Paris: Université de Paris, 116pp, 1944.

MAPA - Ministério da Agricultura, Pecuária e Abastecimento. 2012. Disponível em http://www.agricultura.gov.br/vegetal/culturas/feijao/saiba-mais. Acessado 13 maio 2014.

PREVEDELLO, C. L. Física do solo com problemas resolvidos. Curitiba: SaleswardDiscovery, 1996. 
SANTOS, Maria J. Z. dos. Mudanças climáticas e o planejamento agrícola. p. 65-80. In: SANT'ANNA NETO, J.L.; Zavatini, J. A. Variabilidade e mudanças climáticas: implicações ambientais e socioeconômicas. Maringá: Eduem, 2000. 259p. p.65-80

SCHÖFFEL, EDGAR RICARDO ; MENDEZ, M.E.G. . Influência da insolação e do tipo de superfície sobre o perfil da temperatura do solo. In: Anais do XIV Congresso Brasileiro de Agrometeorologia, 2005, Campinas: Sociedade Brasileira de Agrometeorologia e UNICAMP, 2005. v. 1

SEAB - Secretaria da Agricultura e Abastecimenbto. Olericultura de Conjuntura Agropecuária, $2012 . \quad$ Disponível em http://www.agricultura.pr.gov.br/arquivos/File/deral/Prognosticos/olericultura_2012 13.pdf. Acesso em 15 abril 2014.

SEAB/DERAL. Escritorio Regional de Guarapuava. Consulta direta a dados historicos da região. 2013.

SENTELHAS, P. C. Aspectos climáticos para a viticultura tropical. Informe Agropecuário, Belo Horizonte, 19:9-14, 1998.

TAVARES, Silvio e MELO, Paulo C.T. Cultura da Batata. Piracicaba: ESALQ - Divisão de biblioteca e documentação, (SERIES PRODUTOR RURAL,18), 29p., 2002.

Recebido em agosto de 2014.

Aceito em fevereiro de 2016. 